\title{
Self-enforcing agreement in cooperative teams: an agent-based modeling approach
}

\author{
Hang Xiong ${ }^{1,2^{*}}\left(\mathbb{D}\right.$, Stephen Kinsella ${ }^{3}$ and Diane Payne
}

\author{
*Correspondence: \\ hang.xiong@kcl.ac.uk \\ 2 Department of Geography, \\ King's College London, \\ London, UK \\ Full list of author information \\ is available at the end of the \\ article
}

\begin{abstract}
Purpose: In cooperative teams (such as agricultural cooperatives), self-enforcing agreement plays a critical role in guaranteeing members' work incentives when the monitoring from a third party is absent. In order to provide an effective sanction to the violators so as to maintain the agreement, two seemingly conflicting strategies are proposed. One is allowing the members to exit the team freely. The other is imposing a high exit cost to restrict members from leaving the team. The arguments behind each strategy are elaborated in Lin (J Comp Econ 17:504-20, 1993) and Dong and Dow (J Comp Econ 17:472-84, 1993), respectively. However, these strategies have never been tested in the same model. In fact, no formal model is presented for one of the arguments. To fill this gap, we develop a model that incorporates the two arguments as two scenarios in a shared framework.
\end{abstract}

Methods: An agent-based model is developed to test the two competing hypotheses in the theory of self-enforcing agreement. The model takes heterogeneity of team members (e.g., their laziness, work ability and patience to future well-being) into consideration, which allows us to better understand the divergence of these two arguments.

Results: Using the agent-based model, we conduct computational experiments for testing the two hypotheses. Estimation on the experiment outputs show that (1) The sustained discount rate is lower in exit-free cooperative teams than exit-restricted ones when shirking members exist, which confirms the argument of Lin (J Comp Econ 17:504-20, 1993), and (2) The sustained discount rate is lower in exit-restricted teams than exit-free ones when members' leisure preferences are not too diverse and the economics of scale are not too large, or when the sizes of the teams are large enough, which verifies the argument of Dong and Dow (J Comp Econ 17:472-84, 1993).

Conclusion: We find the two arguments essentially claim different consequences under different conditions of members' characteristics and team size. Our study demonstrates agent-based simulation can be an effective approach of testing game theoretical arguments and exploring game theoretical ideas.

Keywords: Self-enforcing agreement, Exit rights, Exit costs, Agent-based model

\section{Background}

Resource allocation in cooperative organizations can achieve long run efficiency (Chinn 1979; Dwight Israelseni 1980; Norman Cameron 1973; Putterman 1980). Given certain

(c) 2016 The Author(s). This article is distributed under the terms of the Creative Commons Attribution 4.0 International License (http://creativecommons.org/licenses/by/4.0/), which permits unrestricted use, distribution, and reproduction in any medium, provided you give appropriate credit to the original author(s) and the source, provide a link to the Creative Commons license, and indicate if changes were made. 
conditions, the work incentives of team production can be higher than private production (Hamilton et al. 2003; Hansen 1997; Nalbantian and Schotter 1997). However, although some successful cases can be found (e.g. Mondragon Corporation in Spain, Kibbutz in Israel, Plywood agricultural collective in the U.S.), the policy of agricultural collectivization ended up as a failure in most countries (Lin 1993). Studies on the theory of team production since the 1970s have indicated the failure is due mainly to free-riding among members caused by the weak relationship between their efforts and their rewards (Alchian and Demsetz 1972; Meade 1972). Holmstrom (1982) offers a systematic proof in terms of the free rider problem which generalises to moral hazard in a multi-agent setting. Most economists emphasize the importance of perfect monitoring on the efficiency of team production. It is difficult to generate high levels of efficiency in teams or cooperatives with imperfect or costly monitoring.

Monitoring strategies in cooperative teams can be classified as either third party monitoring or mutual monitoring. Teams which have difficulty being monitored by third parties may be efficient if mutual monitoring can be successfully implemented. The theory of self-enforcing agreement studies the efficiency of mutual monitoring in team production. An agreement or contract enforced only by two involved parties rather than a third party or other voluntary tools can be defined as a self-enforcing agreement. Telser (1980) claims parties to an agreement can make it self-enforcing if this is cheaper than resorting to a third party, such as the court. A self-enforcing agreement can remain in force, provided both parties can be better off by honouring it instead of violating it. In a self-enforcing agreement, the only punishment that could be imposed on the violator is terminating the agreement. A party will remain faithful to an agreement if the future loss caused by ending it is larger than the immediate gain from violating it. Telser (1980) surmises a self-enforcing agreement is such that adherence is more advantageous than violation satisfies the following conditions: (a) the game between two parties is infinite, or the end is uncertain or unknown; (b) the duration of the agreement must be long enough; and (c) violations are not expected.

An agreement can be effective only if the threat to punish the violators of the agreement it claims is credible. Macleod (1988) models cooperation in team production as a multi-period repeated game and argues that a retaliation strategy can lead to sub-game perfect equilibrium if it is credible. The retaliation strategy is that the team members can become shirkers themselves if they observe other members shirking. Such mutual shirking will lead to losses for every member. Knowing this is going to be the situation, nobody will start to shirk. The sufficient conditions under which the retaliation strategy works are: (a) the members can keep observing the aggregate output of the team; (b) the general possibility that members leave the team is low, i.e., there are restrictions for a member to exit the team. Macleod (1988) showed the efficiency of team production can be sustained given sufficiently frequent monitoring and low mobility of members. Macleod's model indicates the existence of cooperative equilibrium requires high exit costs for the members. Thus only if the exit costs are high enough so that leaving the team is impossible, the threat strategy is credible.

Lin $(1988,1990)$ argues for the free right to exit according to his observations of agricultural cooperative movements in China, which suggests cooperation could be sustained only when household members had the right to leave the team when they had 
detected shirking members. If exiting the team is not restricted, the hard workers can leave the team when they find shirking members. This will lead to a collapse of the cooperation, and all members will return to private production, in which case they will all lose the economies of scale they could gain from collective production. This threat can reduce shirking behaviour and thus guarantee a team to be at least as efficient as the private production. Therefore, the free right to exit for each member is an necessity for a high-effort equilibrium in cooperative teams (Lin 1993).

Lin's argument generated a heated debate in the literature. The Journal of Comparative Economics held a special symposium over the debate in 1993. Arguments against Lin's (Dong and Dow 1993; Kung 1993; Macleod 1993; Liu 1993; Putterman and Skillman 1993a) are generally based on Macleod's model. Notably, Dong and Dow (1993) present a model to examine the one-shot effort supply game and its corresponding repeated game. Their model demonstrates that mutual shirking imposes a more severe penalty than free exit rights, if the members' payoff from private production is higher than unilateral shirking in a cooperative team, whereas free exit rights could weaken the penalty because the shirking members can flee after shirking. In addition, free exit rights can even lead to the collapse of an efficient team and the sacrifice of scale economics if members use their trigger strategy. Their conclusion is that teams can more readily extract effort if they restrict exit when members' preferences for leisure are not too diverse and scale economies are not too extensive. Moreover, if the teams are sufficiently large, the exit restrictions yield stronger work incentives than exit rights whenever private production is viable. Imposing an exit cost is therefore necessary for the maintenance of any self-enforcing agreement, as originally presented in Macleod (1988).

Putterman and Skillman (1993b) try to unify the two arguments. Based on Abreu (1988)'s notion of optimal penal codes, their model suggests the scope for effective enforcement is directly related to the cost of exit. Macleod's argument and Lin's argument are in fact various extensions of a more general model. They examine two different types of team members: Macleod (1988) and Dong and Dow (1993) study the type of workers has the incentive to shirk and then quit the cooperative, whereas Lin (1993) discusses the type of worker may have the incentive to shirk on a continuing basis and stay in the cooperative.

In his conclusive comments to the debate, Macleod (1993) points out the debate exists because Lin does not provide a formal game theoretical model. The equilibrium of a game can typically be explored once the game is well-defined. In addition, the conclusion could vary when more complicated issues, for instance, the problem of renegotiationproofness, are taken into consideration. Over the past 20 years, much progress has been made on developing the original model (for example, Bond 2009; Faillo et al. 2015; Goldlücke and Kranz 2013; Miller and Watson 2013; Ray 2002). The two competing arguments have never been formally tested and thus the debate has never been concluded.

The present study will explicitly model the competing arguments using an agent-based model approach. This approach enables us to compare the outcomes of the two arguments by modeling all contextual factors and incorporate heterogeneity of households that might have a substantial impact on the outcomes (such as their leisure preferences, time preferences and marginal products of their effort). This study is an exercise in 
demonstrating that agent-based simulation can be an effective approach to explore the outcomes of game theoretic models.

\section{Methods}

Model design

Lin (1993) and Dong and Dow (1993) provide typical elaboration of the two competing arguments. The essential hypotheses that the two arguments hold are below:

Hypothesis 1 (Lin 1993) As long as $j$-type members exist, the free right to exit is a necessary condition for high-effort equilibrium, i.e. in the absence of free exit rights, the high-effort equilibrium cannot be sustained.

Note: $j$-type members are those whose utility when they shirk (denoted as $u_{j}^{n}$ ) is higher than their utility gained from cooperative production (denoted as $u_{j}^{c}$ ), and the utility gained from cooperative production is higher than the utility gained from private farming (denoted as $u_{j}^{p}$ ). That is, $u_{j}^{n}>u_{j}^{c}>u_{j}^{p}$ holds (Lin 1993; Liu 1993).

Hypothesis 2 (Dong and Dow 1993) Restricting member exit can lead a team to more readily extract effort in either of two contexts:

1. Team members' preferences for leisure are not too diverse and the scale economies are not too large.

2. The team is sufficiently large and private production is viable.

To facilitate the comparison, we follow Lin (1990) and Dong and Dow (1993)'s assumptions of production function, utility function and their rules of distribution. We also use collective farming in production teams in China as the reference to build the model. The utility function of a household is

$$
u_{i}\left(y_{i}, e_{i}\right)=y_{i}-v_{i}\left(e_{i}\right), \quad i=1 \ldots n
$$

where $n$ is the number of households in a production team. $u_{i}, y_{i}$, and $e_{i}$ are utility, income and effort of household $i$, respectively. $v_{i}\left(e_{i}\right)$ is a function of the disutility of household effort. Following Dong and Dow (1993)'s assumption, we assume

$$
y_{i}=\theta_{i} e_{i}-F, \quad e_{i} \geq F / \theta_{i}
$$

where $\theta_{i}$ indicates Household $i$ 's marginal product of effort, $F$ is the fixed set-up cost for achieving positive output. In order to satisfy $v_{i}^{\prime \prime}>0, v_{i}^{\prime}>0$, and $/, v_{i}(0)=0$, we assume

$$
v_{i}\left(e_{i}\right)=\alpha_{i} e_{i}^{2}
$$

where $\alpha_{i}$ is the marginal rate of the substitution of income and leisure. This value is set to be between 0 and 1. Let $E=\sum_{k=1}^{n} e_{k}$ to be the total effort and $\Theta=\frac{1}{n} \sum_{k=1}^{n} \theta_{k}$ to be the average marginal product of effort of a team. The production function of a team is

$$
Q=\Theta E-F, \quad 0 \leq E \leq F / \Theta
$$

Outputs are equally distributed among household members in production teams. The income of a household is 


$$
y_{i}=\frac{1}{n}\left[\left(\frac{\sum_{k=1}^{n} \theta_{k}}{n} \sum_{k=1}^{n} e_{k}\right)-F\right] \text {, }
$$

which gives

$$
y_{i}=\frac{\Theta E-F}{n},\left(\Theta=\frac{1}{n} \sum_{k=1}^{n} \theta_{k}, E=\sum_{k=1}^{n} e_{k}\right) .
$$

Since output cannot be negative, it is required that set-up costs are covered i.e. $E \geq F / \Theta$.

For private households, optimal effort is the solution of the function

$$
\max _{e_{i}}\left[\left(\theta_{i} e_{i}-F\right)-\alpha_{i} e_{i}^{2}\right]
$$

The optimal effort of private farming is

$$
e_{i}^{*}=\frac{\theta_{i}}{2 \alpha_{i}} \quad i=1 \ldots n
$$

In collective farming, households can choose to work hard or shirk. Cooperation means the team maximizes the total utility of its members:

$$
\max _{e_{1} \cdots e_{n}}\left(\theta_{j} e_{j}-\alpha_{j} e_{j}^{2}\right)-F
$$

Since economies of scale do not affect marginal returns to effort, cooperative households will choose the same effort as those in private farming. The effort vector an efficient team adopts is $e^{*}=\left(e_{1}^{*} \cdots e_{n}^{*}\right)$.

Following Dong and Dow (1993), we assume households in cooperative teams know how much effort all other members expended in the previous period, i.e. all the households detect the presence of shirking in the period after which it occurs. We also assume that households use the Grim trigger strategy. That is, a household will implement a punishment indefinitely once a household shirks. In this case, the household will not cooperate with other households any longer. They will choose an optimal effort given the lowest effort level they believe other households will take (zero, in this case).

Non-cooperation means that a household member chooses the optimal effort given other households' efforts. Household $i$ solves the function

$$
\max _{e_{i}}\left\{\left[\frac{1}{n}\left(\Theta\left(e_{i}+\sum_{j \neq i} e_{j}\right)-F\right)\right]-\alpha_{i} e_{i}^{2}\right\} .
$$

As given in Dong and Dow (1993), the solution satisfies the following first-order condition

$$
\frac{\theta}{n}=v_{i}^{\prime}\left(e_{i}^{N}\right)
$$


This is in fact an assumption that $e_{j}=0$.

Given $e_{j}=0$, the equation becomes $\max _{e_{i}}\left\{\left[\frac{1}{n}\left(\Theta e_{i}-F\right)\right]-\alpha_{i} e_{i}^{2}\right\}$. Solving it out, we obtain the optimal effort

$$
e_{i}^{N}=\frac{\Theta}{2 n \alpha_{i}} .
$$

All households are in a production team at the initial stage. While being obliged to farm independently (i.e., with free rights to exit), they can choose to stay in a production team and work hard or shirk, or turn to private farming. If exiting is restricted, they can only choose to work hard or shirk.

We assume the households apply the Grim trigger strategy in the repeated game. Household $i$ using the Grim trigger acts in the following manner.

1. Work hard by choosing $e_{i}^{*}$ in the initial period;

2. Keep working hard if no member shirks by deviating from $e_{i}^{*}$ (i.e. choosing $e_{i}^{N}$ in this case) or;

3. Start shirking if the payoff of one-period shirking (i.e., shirking once and receiving punishment in subsequent periods) is greater than the payoff of keeping working hard;

4. Implement punishment in subsequent periods if any member shirks.

\section{The ODD protocol model}

Purpose

The purpose of the model is to test which disciplining device is more effective in maintaining the self-enforcing agreement in cooperative work teams. The model simulates two competing disciplining devices, freeing an exit right and imposing an exit cost. Individual members in a cooperative team decide to work hard, shirk or exit the team (in the case when exit is allowed), reacting to the utilities they obtain under a specific disciplining device. We use collective farming in agricultural cooperatives in China as the reference to build the model.

\section{Entities, state variables and scales}

There are two types of agent in this model: household and team. Team represents an agricultural cooperative, whereas household represents the household members in an agricultural cooperative. A team consists of a number of households, as in any agricultural cooperative.

Variables at the household-agent level are listed in Table 1.

Variables associated with the team-agents are listed in Table 2.

\section{Process overview and scheduling}

According to two disciplining devices, the model simulates the processes of two scenarios: the exit-right scenario and the exit-cost scenario. In both scenarios, households choose to work hard initially i.e., using the effort of $e_{i}^{*}$. In the iteration periods, if households observe nobody shirking, they decide whether they are going to shirk by comparing the payoff of one-period shirking and the payoff of keeping working hard, i.e., 
Table 1 Household-level variables

\begin{tabular}{lll}
\hline Variable & Data type & Value \\
\hline Shirk status (shirk) & Boolean & 1 if shirk, 0 otherwise \\
Exit status (exit) & Boolean & 1 if shirk, 0 otherwise \\
Type status (j-type) & Boolean & 1 if j-type, 0 otherwise \\
Leisure preference (alpha) & Floating-point & {$[0,1]$} \\
Time preference (delta) & Floating-point & {$[0,1]$} \\
Marginal product of effort (theta) & Integer & {$[1,10]$} \\
Fixed cost (fixcost) & Integer & {$[5,30]$} \\
Working effort (effort) & Floating-point & Model output \\
Output yield by production (yield) & Floating-point & Model output \\
Utility (utility) & Floating-point & Model output \\
Sustained discount rate (discount ${ }^{\mathrm{a}}$ ) & Floating-point & Model output \\
\hline
\end{tabular}

a Sustained discount rate is an indicator provided in Dong and Dow (1993). It measure how cooperation is sustained for households. It can be used to indicate the sustainability of a team (this is elaborated in the "Results" section)

Table 2 Attribute of the team agent

\begin{tabular}{lll}
\hline Variable & Data type & Value \\
\hline Population (population) & Integer & {$[10,100]$} \\
Threshold to dismiss a team (dismiss-rate) & Floating-point & {$[0.4,0.8]$} \\
Number of shirked households (shirk-num) & Floating-point & Model output \\
Number of exited households (exit-num) & Floating-point & Model output \\
Average sustained discount rate (ave-discount) & Floating-point & Model output \\
\hline
\end{tabular}

$\frac{1}{1-\delta} u_{i}^{C}$. If the latter is larger, they choose to shirk. Otherwise, they keep working hard. The payoff of one-period shirking is different in the exit-right and exit-cost scenarios, as the punishment following the shirking is different. Specifically, the punishment is private working in the exit-right scenario and is non-cooperation in the exit-cost scenarios. The payoff of one-period shirking is $u_{i}^{S}+\frac{\delta}{1-\delta} u_{i}^{P}$ in the exit-right, whereas $u_{i}^{S}+\frac{\delta}{1-\delta} u_{i}^{N}$ in the exit-cost scenarios. If households observe a shirking household, those in the exit-right scenario can choose whether to shirk themselves or exit the team by comparing the pay-

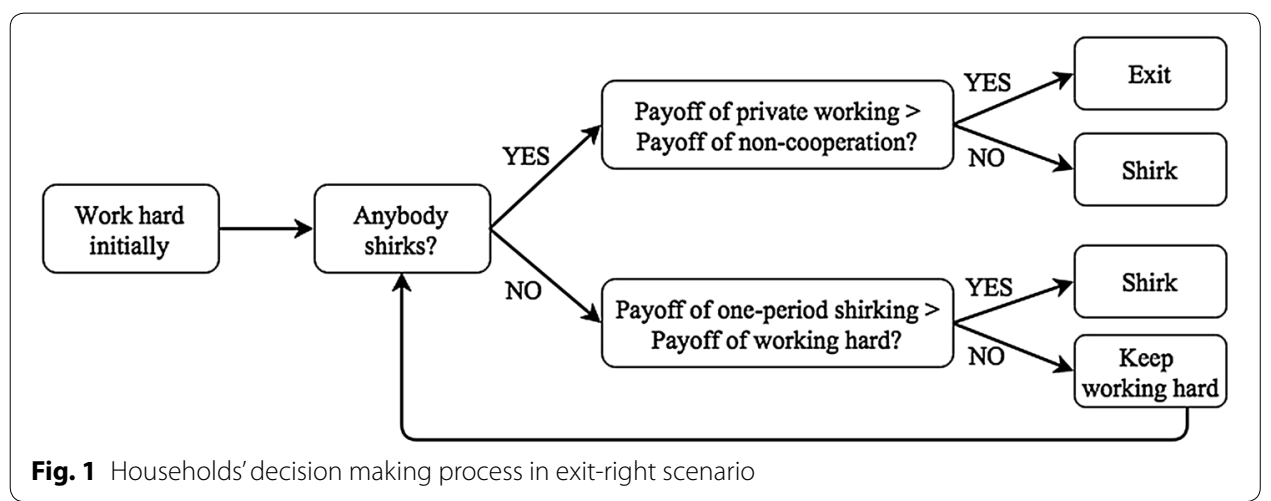

off of non-cooperation, i.e., $u_{i}^{N}$, and the payoff of private working, i.e., $u_{i}^{P}$, whereas those 


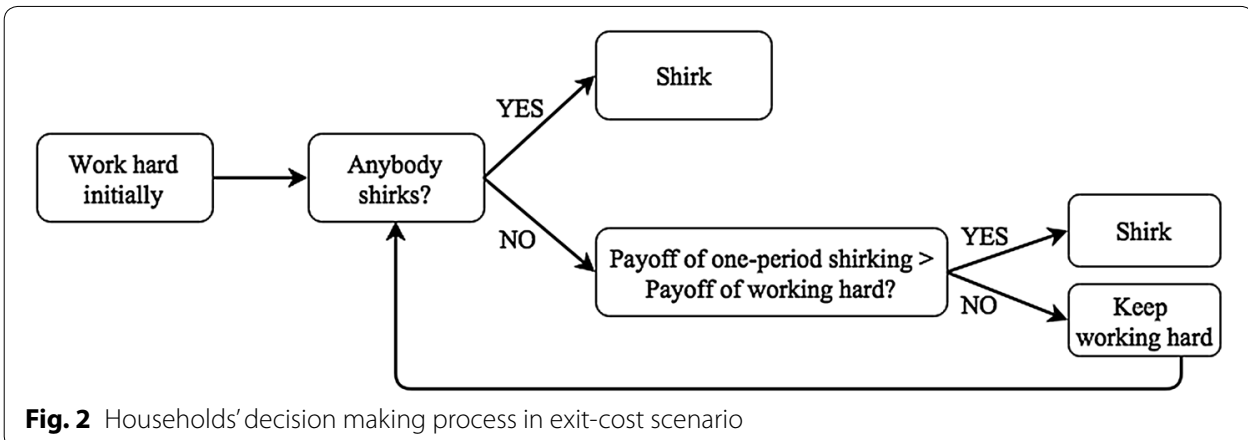

in the exit-cost scenario can only choose to follow suit. In each simulation, the whole process repeats for ten times (by which over $90 \%$ of the cases have converged, according to our experimental running) or until the team is dismissed (in the exit-right scenario).

Figures 1 and 2 illustrate the processes in the exit-right and exit-cost scenario, respectively.

\section{Design concepts}

Emergence For the purposes of evaluating which disciplining device is more effective, we explore the average sustained discount rates (which indicate the sustainability of a team that a disciplining device leads to), the average effort and the average utility (which together indicate the outcome of a disciplining device) of households in a team. They are emergent in the sense that they are the results of the decentralised decisions of households.

Adaptation (how the agents adapt their behaviour to their and their environments current state) In each round, households update their decisions, to keep working hard, to shirk or to exit the team (in the exit-right scenario) according to their payoff as a result of the decision of their fellow households.

Objectives Households aim to maximize the current utility they obtain and the discounted future utility they could obtain when they make decisions.

Prediction Agents in the model generally do not predict. Households, however, are able to calculate their future utility by assuming that their fellows will keep working hard if they observe nobody shirking and assuming that their fellow households will adopt the Grim trigger strategy when they shirk.

Sensing Households are assumed to know all other households' decisions in the last period, but not in the present period.

Stochasticity The model deliberately avoids introducing stochasticity, as it was designed to extend other deterministic models. The only potential source of stochasticity is households' time preference, leisure preference, marginal product of effect and fixed cost, which are generated based on different distributions (normal, Poisson or exponential distribution). 
Observation (how data are gathered from the model) Various observations are available to produce by the model, from an omniscient perspective, as it were. However, the key observations we are interested are the effort that households make, the utility they gain, and their sustained discount rate. The rate of households who exit the team is also observed in the exit-right scenario.

\section{Initialization}

The state of the model is initialised by setting an initial configuration of agent attributes. All household agents are initialized as being in a cooperative (exit status) and working hard (shirk status). The initial values of households' leisure preference, time preference, marginal product of effect and fixed cost are chosen arbitrarily, with several runs used to determine the typical behaviour of the model using a statistical test (shown in Table 3). Whether a household is of $j$-type is determined once its marginal product of effort (theta) and the fixed cost (fixcost) are determined.

\section{Input}

Following the initialisation, household conditions remain constant over and time in the model. There are two scenarios, in which households are allowed to exit their teams or not. In the exit-right scenario, households are allowed to exit from the team when private working is more beneficial for them. In the exit-cost scenario, households are not allowed to exit under any circumstances.

\section{Sub-models}

Households choose their effort to optimize their utilities in four cases: private working, cooperation, non-cooperation, unilateral shirking (given all households using Grim strategy). The optimal efforts in the four cases are calculated as below.

Private farming

$$
u_{i}^{P}\left(e_{i}^{*}\right)=\left(\theta_{i} \frac{\theta_{i}}{2 \alpha_{i}}-F\right)-\alpha_{i}\left(\frac{\theta_{i}}{2 \alpha_{i}}\right)^{2}
$$

Solving the FOC yields:

$$
u_{i}^{P}\left(e_{i}^{*}\right)=\frac{\theta_{i}^{2}}{4 \alpha_{i}}-F
$$

Table 3 Household-level variables

\begin{tabular}{lc}
\hline Variable & Initial value \\
\hline Leisure preference (alpha) & {$[0: 0.1: 1]^{\mathrm{a}}$} \\
Time preference (delta) & {$[0: 0.1: 1]$} \\
Marginal product of effort (theta) & {$[1: 1: 10]$} \\
Fixed cost (fixcost) & {$[5: 5: 30]$} \\
Population (population) & {$[10: 10: 100]$} \\
Threshold to dismiss a team (dismiss-rate) & {$[0.4: 0.2: 0.8]$}
\end{tabular}

a It means incrementing from 0 to 1 , with the interval of 0.1 . Similarly, hereinafter 
Cooperation in collective farming

$$
u_{i}^{C}\left(e_{i}^{*}\right)=\frac{1}{n}\left[\Theta\left(\frac{\theta_{1}}{2 \alpha_{1}}+\cdots+\frac{\theta_{i}}{2 \alpha_{i}}+\cdots+\frac{\theta_{n}}{2 \alpha_{n}}\right)-F\right]-\alpha_{i}\left(\frac{\theta_{i}}{2 \alpha_{i}}\right)^{2}
$$

Solving the FOC yields:

$$
u_{i}^{C}\left(e_{i}^{*}\right)=\frac{\Theta}{2 n}\left(\frac{\theta_{1}}{\alpha_{1}}+\cdots+\frac{\theta_{i}}{\alpha_{i}}+\cdots+\frac{\theta_{n}}{\alpha_{n}}\right)-\frac{\theta_{i}^{2}}{4 \alpha_{i}}-\frac{F}{n} .
$$

Non-cooperation in collective farming

$$
u_{i}^{N}\left(e_{i}^{N}\right)=\frac{1}{n}\left[\Theta\left(\frac{\Theta}{2 n \alpha_{1}}+\cdots+\frac{\Theta}{2 n \alpha_{i}}+\cdots+\frac{\Theta}{2 n \alpha_{n}}\right)-F\right]-\alpha_{i}\left(\frac{\Theta}{2 n \alpha_{i}}\right)^{2}
$$

Solving the FOC yields:

$$
u_{i}^{N}\left(e_{i}^{N}\right)=\frac{\Theta^{2}}{2 n^{2}}\left(\frac{1}{\alpha_{1}}+\text { cdots }+\frac{1}{\alpha_{i-1}}+\frac{1}{\alpha_{i+1}}+\cdots+\frac{1}{\alpha_{n}}\right)+\frac{\Theta^{2}}{4 n^{2} \alpha_{i}}-\frac{F}{n} .
$$

Unilateral shirking (trigger strategy)

$$
u_{i}^{S}\left(e_{i}^{N}, e_{-i}^{*}\right)=\frac{1}{n}\left[\Theta\left(\frac{\theta_{1}}{2 \alpha_{1}}+\cdots+\frac{\Theta}{2 n \alpha_{i}}+\cdots+\frac{\theta_{n}}{2 \alpha_{n}}\right)-F\right]-\alpha_{i}\left(\frac{\Theta}{2 n \alpha_{i}}\right)^{2}
$$

Solving the FOC yields:

$$
u_{i}^{S}\left(e_{i}^{N}, e_{-i}^{*}\right)=\frac{\Theta}{2 n}\left(\frac{\theta_{1}}{\alpha_{1}}+\cdots+\frac{\theta_{i-1}}{\alpha_{i-1}}+\frac{\theta_{i+1}}{\alpha_{i+1}}+\cdots+\frac{\theta_{n}}{\alpha_{n}}\right)+\frac{\Theta^{2}}{4 n^{2} \alpha_{i}}-\frac{F}{n} .
$$

\section{Results}

The simulation was repeated 1000 times for each parameter combination. We use the mean over the 1000 repetitions as the value of each variable in our simulations.

\section{Outcomes of the two disciplining devices}

Different disciplining devices provide different motivations to individual households, and thus leads them to devote different amounts of effort. Accordingly, households obtain different amounts of utility. In order to test how disciplining device affects the outcome of a team in terms of the average effort that households make and the average utility that households obtain, we run regressions over the simulation results using the Eqs. (1) and (2) below. Equation (1) reflects the correlation between household effort (effort) and leisure preference (alpha), time preference (delta), marginal product of effort (theta), and fixed cost (fixcost), whereas Eq. (2) reflects the correlation between household utility (utility) and household effort (effort).

$$
\begin{aligned}
& \text { effort }_{k}=\omega_{1} \text { alpha }_{k}+\omega_{2} \text { theta }_{k}+\omega_{3} \text { delta }_{k}+\omega_{4} \text { fixcost }_{k}+\varepsilon \\
& \text { utility }_{k}=\omega_{1} \text { effort }_{k}+\varepsilon
\end{aligned}
$$




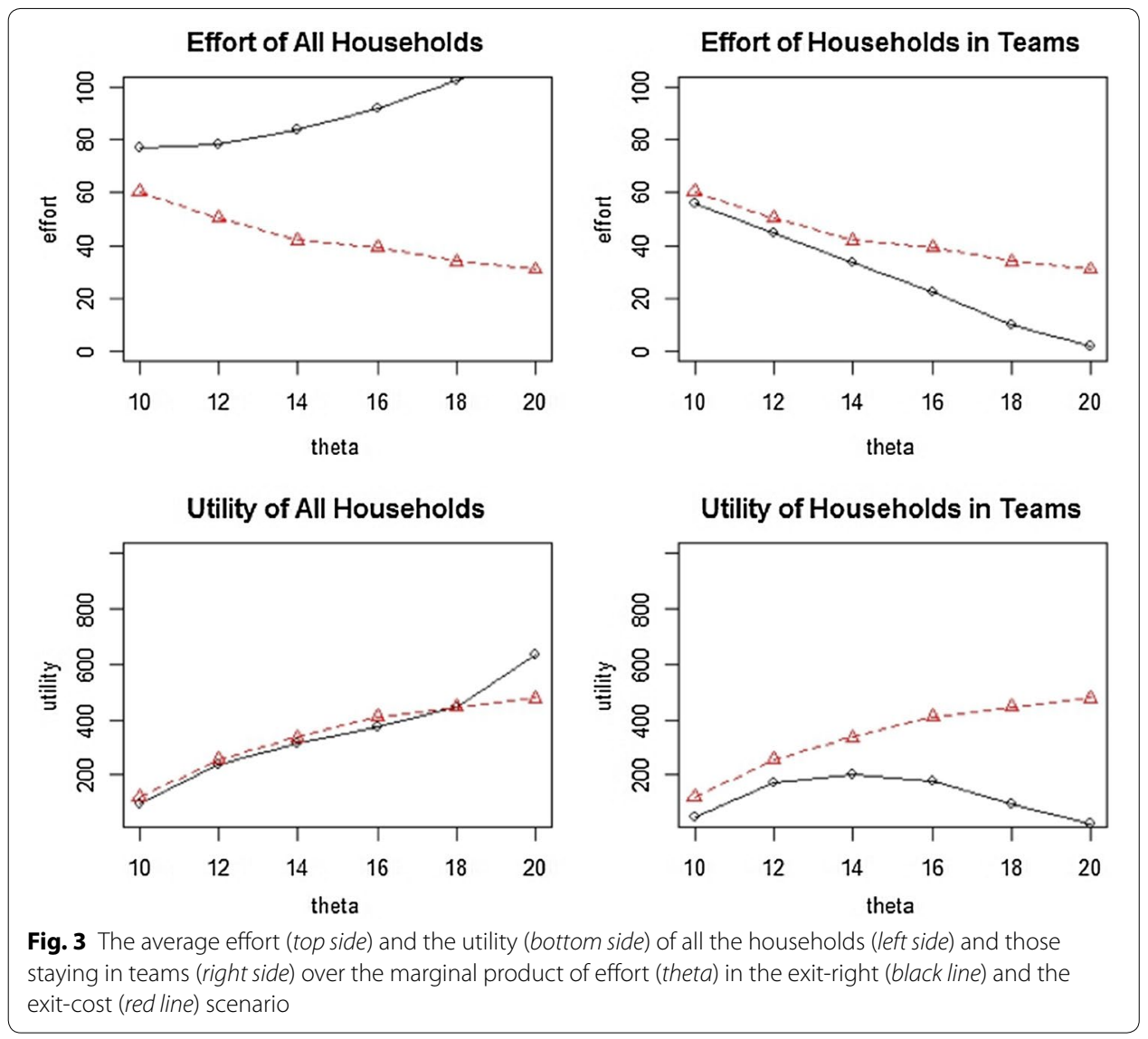

Figures 3 and 4 compare the average effort members input and the average utility members obtain under different levels of the marginal product (theta) in the two scenarios. Both the values of all households and those who stay in teams are calculated to observe the effect of free exit.

Figure 3 shows the average effort of all households is distinctly higher in the exit-right scenario than in the exit-cost scenario, while the contrary is the case for households in teams. This difference increases as the value of theta grows. The average utility of all households is generally close in the two scenarios. The average utility of households in teams is distinctly higher in the exit-cost scenario. As theta grows, in the exit-cost scenario, the average utility of all households increases more rapidly, whereas the average utility of households staying in teams decreases more rapidly.

These results are probably related to the change of the exit rate and the economies of scale. In the exit-right scenario, the exit rate increases as households' marginal products of effort increase, i.e., households have a high ability to produce. Therefore, the average effort over all households increases, while that of the households in teams decreases as theta grows.

A similar pattern is found for average utility. In the exit-cost scenario, the average effort of all households and those remaining in teams decrease as theta grows, due to the increase of the rate of shirking households (i.e., shirking rate). The corresponding 


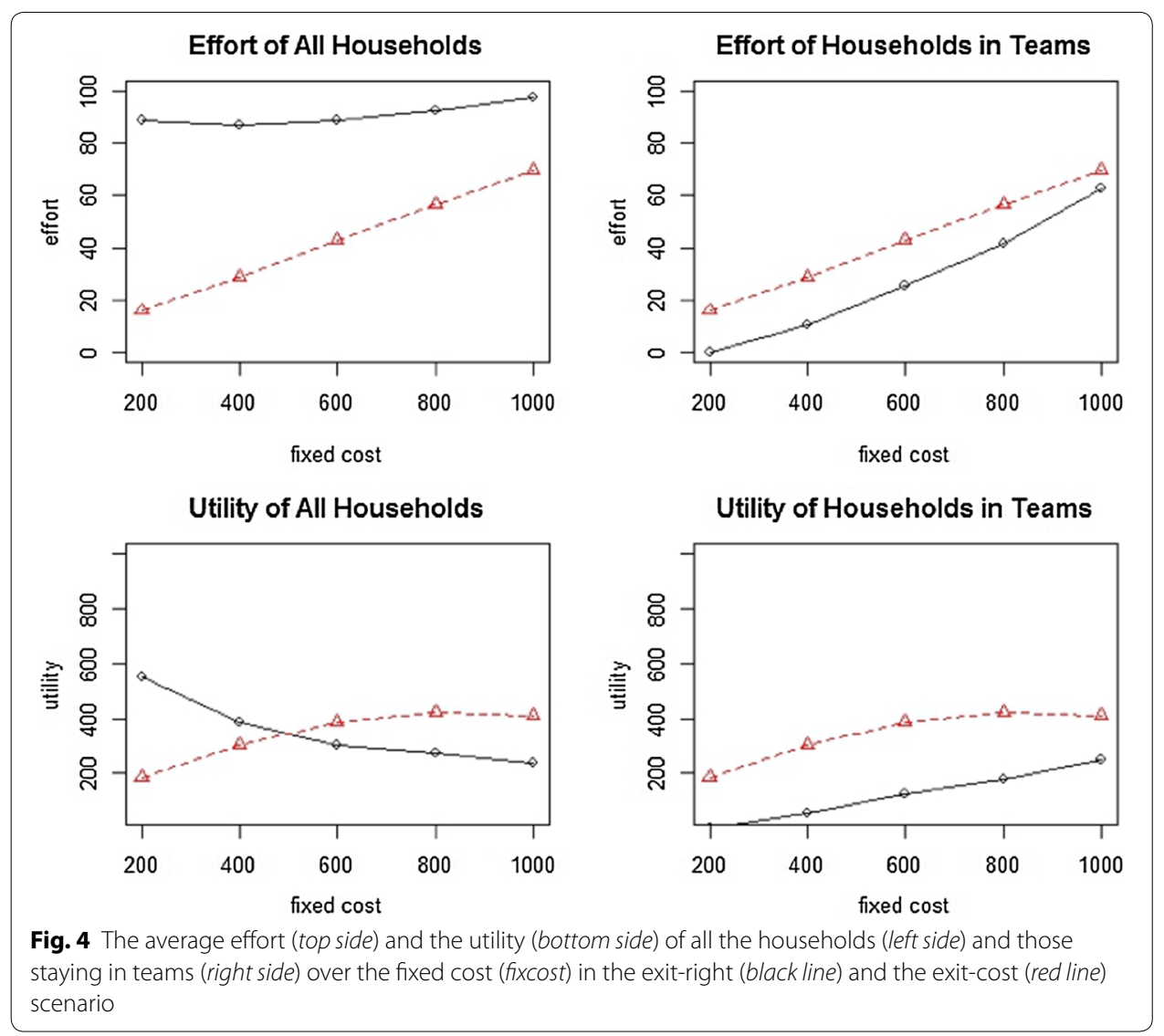

average utility, however, keeps growing and becomes higher in the exit-cost scenario, due to the existence of economies of scale.

Figure 4 indicates quite a similar landscape of comparing results in the two scenarios to Fig. 3. It is worth noting that, as the fixed cost grows, the average utility of all household decreases in the exit-right scenario but increases in the exit-cost scenario. This suggests the exit-cost device outperforms the exit-right in the case of a high economics of scale. However, this could be changed if we take transaction costs, which may increase while the economics of scale grow, into consideration.

In general, the average effort of all households is much higher in the exit-right scenario, whereas the average utility of all households is close in the two scenarios. The average effort and the average utility of households in teams are both higher when exit is restricted. It implies effort levels and utilities of the leaving households are quite high. The difference of the effort level and utility in the exit-free team is obviously higher than in the exit-restricted teams. It also suggests the exit-restricted teams could behave better in limiting the income disparity among members, which provide an explanation to the situation in Chinese agricultural cooperatives in the 1960s and 1970s.

\section{Factors affecting exit rate}

The above section suggests that production ability and economics of scale both influence the exit rate (rate of households that exit a team). To check if the two variables have a 

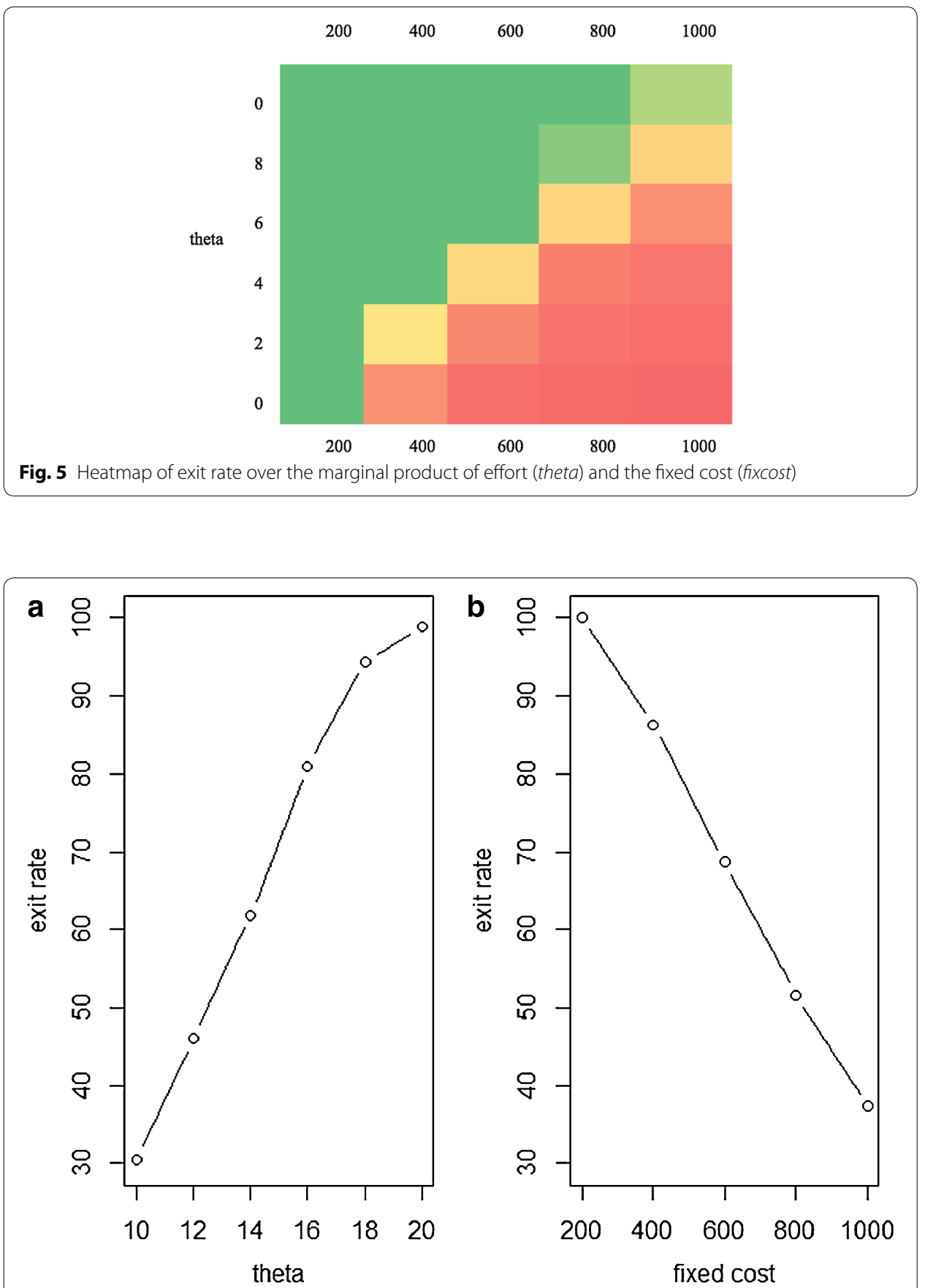

Fig. 6 a Relationship between exit rate and the marginal product of effort (theta); $\mathbf{b}$ Relationship between exit rate and the fixed cost (fixcost)

crossing effect on the exit rate, we first draw a heatmap of the exit rate over the marginal product and the fixed cost (shown in Fig. 5). We find no evidence for the crossing effect from the heatmap because the two colours are not mixed.

Next, we examine the effect of each of them separately. Figure 6a demonstrates the correlation between the exit rate and theta. It shows these two variables are obviously positively correlated, which basically verifies our inference. Meanwhile, Fig. 6b illustrates 
the correlation between exit rate and the fixed cost. The graph also shows an obvious negative correlation, which suggests that the higher the economics of scale that household members can obtain, the less intended they exit.

\section{Necessity of exit-right disciplining device}

According to Lin (1993), the existence of $j$-type households is essential to the debate over the exit-right and the exit-cost disciplining devices. For a $j$-type household, $u_{j}^{N}>u_{j}^{C}>u_{j}^{P}$ establishes. A $j$-type household with a high preference for leisure has an incentive to shirk and stay within the cooperative. If $j$-type households exist in a cooperative, which Lin believes this is for sure for a 100-farmer team, his argument of exit right will be valid, otherwise, Dong and Dow's argument of exit right will be valid.

We first examine what factor(s) affect the existence of $j$-type households and under what condition(s) they exists. Holding other variables, we run the model to test if the gradual changes of marginal product of effort (theta), fixed cost (fixcost), preference for leisure (alpha), preference for future income (delta) and their combinations change the number of $j$-type households. By running the model for 100 times over each combination, we find that only the marginal product of effort (theta) and fixed cost (fixcost) affect the existence of $j$-type households (see Table 4) and the number of them, and whether the exit is free or restricted in the teams makes no difference. According to the result, we believe that $j$-type households do exist in the teams in our model.

It shows $j$-type households certainly exist when the marginal product of effort (theta) is very low ( 2 and lower in this case). As the value of theta increases, $j$-type households exist only when fixed cost (fixcost) is high. No $j$-type household is found when theta is high ( $>6$ in this case). If taking the number of $j$-type household in a team within a particular population into consideration (which we do show in this table for simplicity but quite apparent), it grows as theta decreases and fixcost increases. We, therefore, conclude that the possibility of the existence of $j$-type household is negatively correlated to the marginal product of effort and positively correlated to fixed cost (which represents economies of scale).

This can be explained by (a) the lower the marginal product of households (the ability to produce independently), the higher their willingness to stay in teams; and (b) the higher the economies of scale of a team, the more households can be benefited by staying in the team, which enhance their willingness to stay. This accords with the model's inputs and, helpfully, with common sense.

Next, we test Lin's argument that free exit right works better than restrictive exit right if households have incentive to shirk and stay (which are $j$-type households with high

Table 4 Existence of $j$-type household

\begin{tabular}{ll}
\hline theta & fixcost \\
\hline 2 & $6-20$ \\
4 & $12-20$ \\
6 & $16-20$ \\
\hline theta is set to increases from 2 to 10 in intervals of 2. fixcost is set to increase from 6 to 20 in intervals of 2
\end{tabular}

theta is set to increases from 2 to 10 in intervals of 2 . fixcost is set to increase from 6 to 20 in intervals of 2 
preference for leisure) exist in teams. Based on the above settings where $j$-type households exist, we let preference of leisure (alpha) change from 0.1 to 1 in intervals of 0.1. We use the sustained discount rate $\bar{\delta}$ developed in Dong and Dow (1993) to evaluate which strategy, the exit-right or the exit-cost, play as a better disciplining device. We have:

$$
\bar{\delta}=\frac{u_{i}^{S}-u_{i}^{C}}{u_{i}^{S}-\bar{u}_{i}}
$$

where $\bar{u}_{i}=u_{i}^{P}$ if in exit-right scenario, and $\bar{u}_{i}=u_{i}^{N}$ in exit-cost scenario. A larger value of $\bar{\delta}$ indicates a weaker deterrent effect of the penalty phase because worker $i$ must value the future payoff more highly in order to dissuaded from shirking.

Hypothesis 1 (Lin 1993) concerns the necessity of exit rights for high-effort equilibrium in cooperatives. To test this hypothesis, we test if the sustained discount rate $\bar{\delta}$ is lower when exit is free than restricted under the circumstance where $j$-type households exit. Thus, the following equation is estimated.

$$
\bar{\delta}_{k}=\beta I_{k}+\varepsilon
$$

where $\bar{\delta}_{k}$ is the average effort of production team (i.e. running round in this case) $k$, and $I_{k}$ is an indicator variable which equals 1 when exit is free and 0 otherwise. To demonstrate the difference that might be caused by different distributions of leisure preference, the coefficient of $I_{k}, \beta$, is estimated for the normal, Poisson and the exponential distributions. Table 5 presents the results.

It shows that $I_{k}$ is significant in all the cases. Moreover, its coefficient is negative. This indicates that the sustained discount rate $\bar{\delta}$ is lower in teams with exit rights than teams with exit costs. This result verifies Hypothesis 1.

\section{Sustainability of exit-cost versus exit-right disciplining device}

Hypothesis 2 (Dong and Dow 1993) proposes two independent sufficient conditions under which restricted exit provides lower sustained discount rate $\bar{\delta}$. We shall refer to them as Claim (i) and (ii) respectively hereafter. Claim (i) is related to the diversity of households' leisure preference and scale economies. The diversity of leisure preference is measured by standard deviation of leisure preference (alpha-sd), and scale economies are indicated by the fixed cost (fixcost). To test Claim (i), we estimate the same function as above over different fixed cost and standard deviation of leisure preference respectively. As standard deviations are not available for Poisson and exponential distributions, we only test the standard deviation of leisure preference for the case of the normal distribution.

Table 5 Estimated effect of exit rights on sustained discount rate for testing Hypothesis 1

\begin{tabular}{llll}
\hline Distribution & Normal & Poisson & Exponential \\
\hline Estimate of $\beta$ & $-0.2216^{* * *}(-93.37)$ & $-0.3888^{* * *}(-34.15)$ & $-0.3878^{* *}(-48.05)$ \\
\hline${ }^{* * *}$ and ${ }^{* * *}$ denote significance at the level of $10 \%, 5 \%$ and $1 \%$, respectively &
\end{tabular}



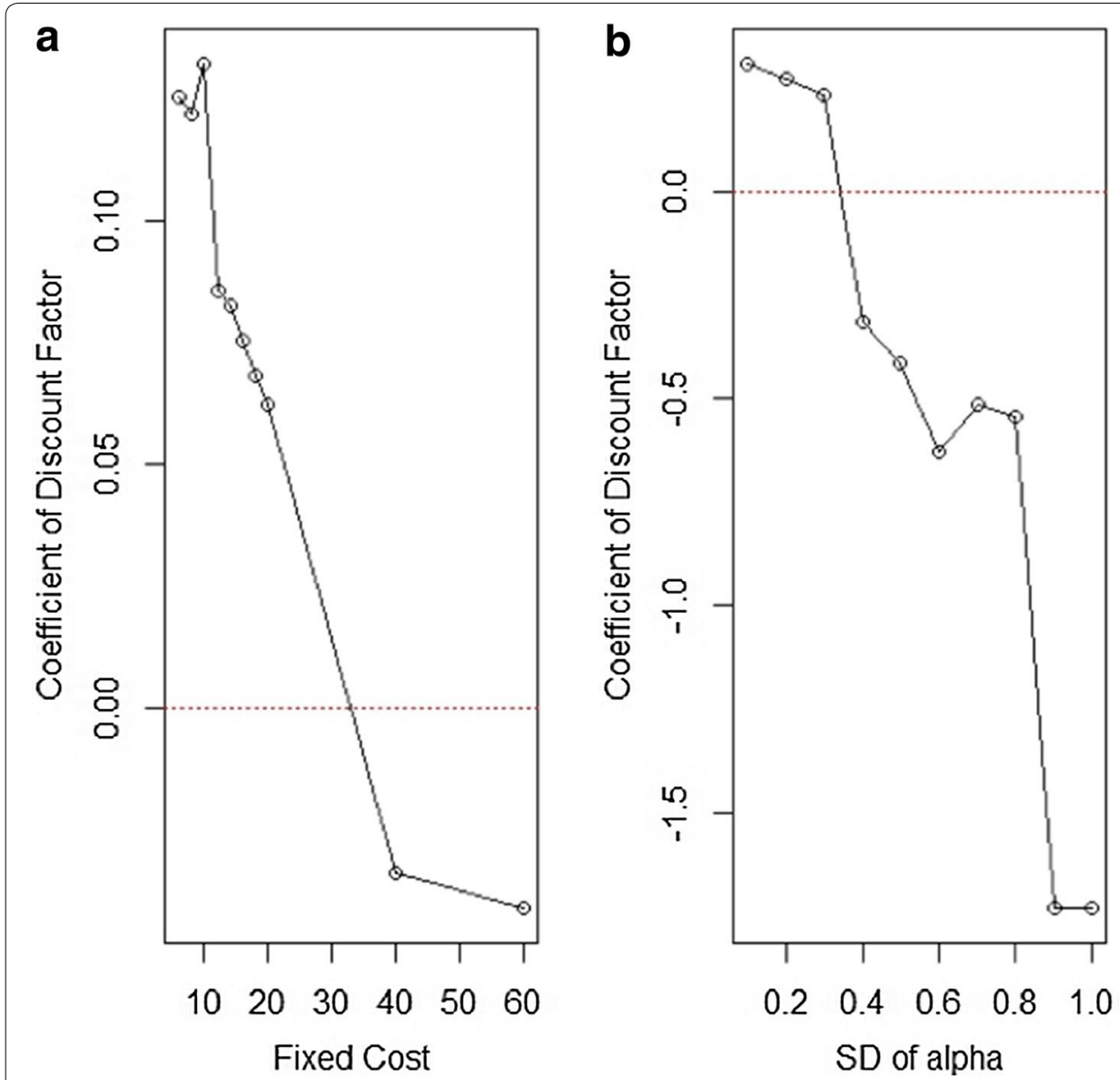

Fig. 7 a Coefficients of sustained discount rate versus fixed cost; $\mathbf{b}$ coefficients of sustained discount rate versus standard deviation of alpha

Figure $7 \mathrm{a}$ shows the coefficient generally decreases as fixed cost grows. In the section where fixed cost is less than a certain level (somewhere between 30 and 40 in this case), the coefficient is positive, which indicates the sustained discount rate $\bar{\delta}$ is lower in cooperatives without exit rights. Figure $7 \mathrm{~b}$ shows a generally negative correlation between the coefficient and standard deviation of alpha. A threshold of fixed cost can be found at somewhere between 0.30 and 0.40 . When fixed cost is less than such threshold, the coefficient is positive, which indicates the sustained discount rate $\bar{\delta}$ is lower in cooperatives without exit rights.

Claim (ii) is related to the team size. We estimate coefficients of sustained discount rate over the number of household in cooperatives in difference distributions. The three plots in Fig. 8 display coefficients of sustained discount rate over the team size for different distributions.

All plots show positive correlations between the coefficient and team scale. As the team size exceeds a certain boundary value, the coefficient changes from negative to positive. This suggests the sustained discount rate $\bar{\delta}$ is lower in cooperatives without exit rights than those with exit rights when the team size is sufficiently large.

Therefore, both the two claims of Hypothesis 2 are verified by the statistical analysis of our simulation outcomes. 


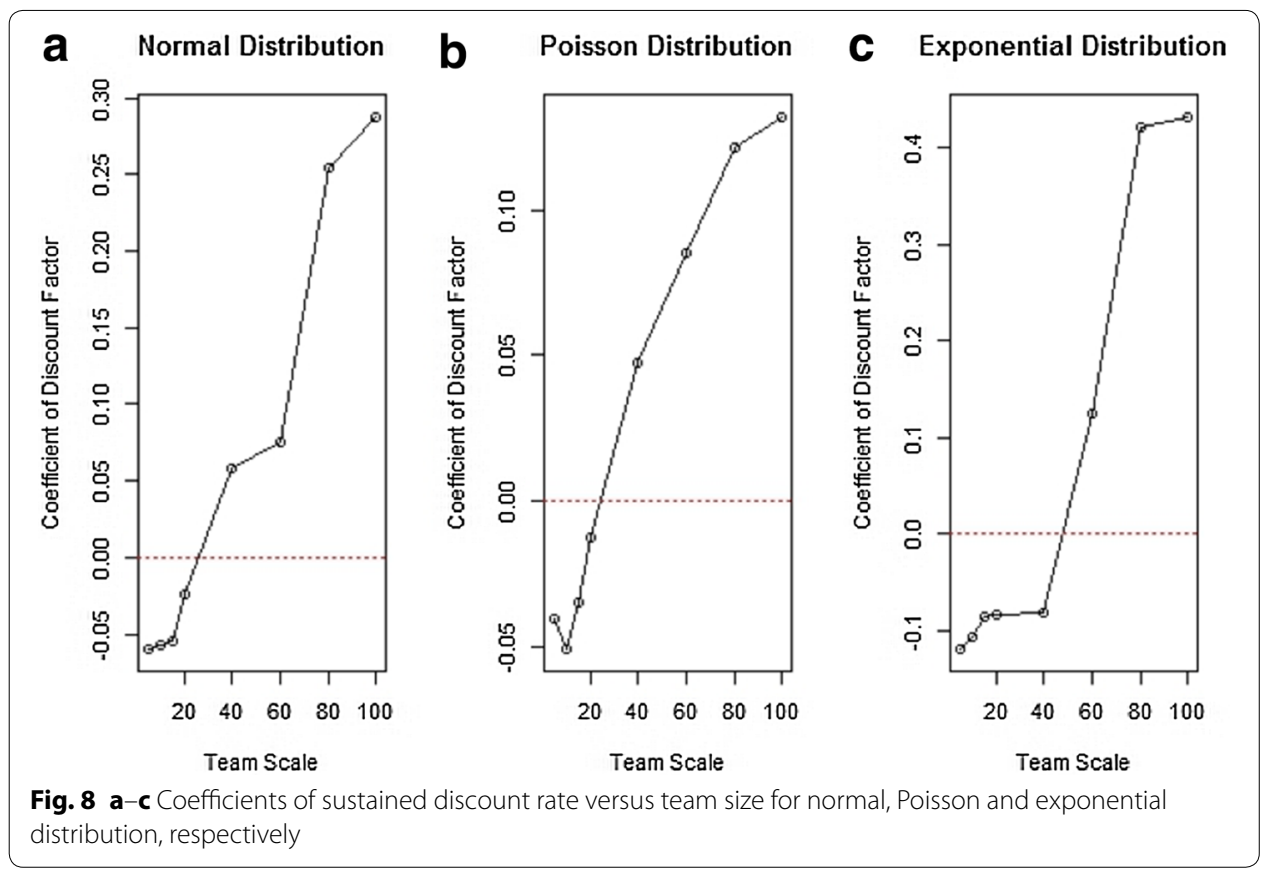

\section{Conclusion}

This study tests two competing arguments in the theories of self-enforcing agreement using agent-based modelling. These arguments were original proposed verbally or as a game theoretical model, and have never been tested in a same framework. Our model explicitly considers the size of the cooperative team in question and the heterogeneity of the members in the team, including their leisure preference (i.e., laziness), time preference (i.e., patience to future well-being) and the marginal product of effort (i.e., work ability). This allows us to better understand the divergence of these two arguments. Statistical analysis over the simulated data shows: (1) the sustained discount rate is lower in exit-free cooperative teams than exit-restricted ones when shirking members exist. This confirms the hypothesis based on the argument of Lin (1993). (2) The sustained discount rate is lower in exit-restricted teams than exit-free ones when members' leisure preferences are not too diverse, and the economics of scale are not too large. A threshold of standard deviation of the leisure preference and the fixed cost are found in our results. This is consistent with Claim (i) of the hypothesis developed based on the argument of Dong and Dow (1993). (3) The sustained discount rate is lower in exit-restricted teams than exit-free ones when the sizes of the teams are large enough. This result verifies Claim (ii) developed based on the argument of the hypothesis of Dong and Dow (1993).

In fact, the two hypotheses argue different consequences under different conditions, and thus suggest different policies for different conditions of members' characteristics in a cooperative team. If there are members whose production is very low when working privately (such as those who are extremely lazy or with very low work ability), giving the members a free right to exit can more readily extract the team's maximum effort. However, in the situation that most members work reasonably hard and can do quite well when working privately, restricting exit would be a better disciplining device. 
This study is a useful exercise showing how agent-based simulation explores insights that game theory approach may find difficulty to achieve. Compared to game theoretical model, agent-based model can incorporate the heterogeneity of individuals more effectively. This often allows researcher to delve into a lower level of the question in discussion and thus reach more insightful conclusion, especially in the cases where heterogeneity of individuals could impose a significant impact on the result.

\section{Authors' contributions}

HX conceived, designed and developed the simulation model. HX and SK performed the simulations and analysed the simulation results. DP actively participated during all research progress in the capacity as project's principal supervisor. HX and SK wrote the paper. All authors read and approved the final manuscript.

\section{Authors' information}

Dr. Hang Xiong is a research associate in the Department of Geography at King's College London. He studies famers' collective action and how it can be shaped by social structure using computational and econometric methods. Dr. Hang Xiong received his Ph.D. at University College Dublin in 2016.

Dr. Stephen Kinsella is a senior Lecturer in the Department of Economics at the University of Limerick. He studies macroeconomic theories and computational economics. Dr. Stephen Kinsella received a Ph.D. at National University of Ireland, Galway in 2007 and a Ph.D. at New School for Social Research, New York in 2010.

Dr. Diane Payne is an associate professor in the School of Sociology at University College Dublin. She studies the field of computational social science, in particular, social network analysis, behavioural models of group processes and collective decision-making. Dr. Diane Payne received her Ph.D. at the University of Groningen.

\section{Author details}

${ }^{1}$ School of Sociology and Geary Institute for Public Policy, University College Dublin, Dublin, Ireland. ${ }^{2}$ Department of Geography, King's College London, London, UK. ${ }^{3}$ School of Economics, University of Limerick, Limerick, Ireland.

\section{Acknowledgements}

The authors would like to convey their sincere appreciation to the anonymous reviewers. Their insightful remarks and suggestions made us able to improve the quality of manuscript.

Competing interests

The authors declare that they have no competing interests.

\section{Funding}

This research is funded by the National Natural Science Foundation of China under the project "Triggering Factors and Evolutionary Mechanism of Cooperative Behaviour on Irrigation"(No. 71303198).

Received: 19 March 2016 Accepted: 25 August 2016

Published online: 01 September 2016

\section{References}

Abreu D (1988) On the theory of infinitely repeated game with discounting. Econometrica 56(2):383-392

Alchian AA, Demsetz H (1972) Production, information costs, and economic organization. Am Econ Rev 62(5):777-795

Bond EW (2009) Paths of efficient self-enforcing trade agreements. Econ Theor 41(1):85-104. doi:10.1007/ s00199-008-0417-x

Cameron Norman (1973) Incentives and labor supply in cooperative enterprise. Can J Econ 6:16-23

Chinn DL (1979) Team cohesion and collective-labor supply in Chinese agriculture. J Comp Econ 3:375-394

Dong X, Dow GK (1993) Does free exit reduce shirking in production teams. J Comp Econ 17:472-484

Dwight Israelseni L (1980) Collectives, communes and incentives. J Comp Econ 4:99-124

Faillo M, Ottone S, Sacconi L (2015) The social contract in the laboratory: an experimental analysis of self-enforcing impartial agreements. Pub Choice 163(3):225-246

Goldlücke S, Kranz S (2013) Renegotiation-proof relational contracts. Games Econ Behav 80:157-178. doi:10.1016/j. geb.2013.02.009

Hamilton BH, Nickerson JA, Owan H (2003) Team incentives and worker heterogeneity: an empirical analysis of the impact of teams on productivity and participation. J Polit Econ. doi:10.1086/374182

Hansen DG (1997) Worker performance and group incentives: a case study. Ind Labor Relat Rev 51(1):37-49. doi:10.2307/2525033

Holmstrom Bengt (1982) Moral hazard in teams.pdf. Bell J Econ 13(2):324-340

Kung JK (1993) Transaction costs and peasants' choice of institutions: did the right to exit really solve the free rider problem in Chinese collective agriculture. J Comp Econ 17:485-503

Lin JY (1988) The household responsibility system in China's agricultural reform: a theoretical and empirical study. Econ Dev Cult Change 36:199-224

Lin JY (1990) Collectivization and China's agricultural crisis in 1959-1961. J Polit Econ 98(6):1228-1252

Lin JY (1993) Exit rights, exit costs, and shirking in agricultural cooperatives-a reply. J Comp Econ 17(2):504-520

Liu M (1993) Exit right, retaliatory shirking, and the agricultural crisis in China. J Comp Econ 17(2):540-559 
Macleod WB (1988) Equity, efficiency, and incentives in Cooperative Teams. Adv Econ Anal Particip Labor-Manag Firms 54:5-23

Macleod WB (1993) The role of exit costs in the theory of cooperative teams: a theoretical perspective. J Comp Econ 17(2):521-529

Meade JE (1972) The theory of labour-managed firms and of profit sharing. Econ J 82(325):402-428

Miller DA, Watson J (2013) A theory of disagreement in repeated games with bargaining. Econometrica 81 (6):2303-2350. doi:10.3982/ECTA10361

Nalbantian HR, Schotter A (1997) Productivity under group incentives: an experimental study. Am Econ Rev 87(3):314341. doi:10.2307/2951348

Putterman LG (1980) Voluntary collectivization: a model of producers'institution choice. J Comp Econ 4:125-157

Putterman LG, Skillman GL (1993a) Collectivization and China's agricultural crisis. J Comp Econ 17(2):530-539

Putterman LG, Skillman GL (1993b) The role of exit costs in the theory of cooperative teams. J Comp Econ 17:596-618

Ray D (2002) The time structure of self-enforcing agreements. Econometrica 70(2):547-582. doi:10.1111/1468-0262.00295

Telser LG (1980) A theory of self-enforcing agreements. J Bus 53(1):27-44

\section{Submit your manuscript to a SpringerOpen ${ }^{\circ}$ journal and benefit from:}

- Convenient online submission

\section{- Rigorous peer review}

- Immediate publication on acceptance

Open access: articles freely available online

- High visibility within the field

Retaining the copyright to your article

Submit your next manuscript at $\boldsymbol{\nabla}$ springeropen.com 